\title{
BioTechniques
}

\section{A robust fractionation method for protein subcellullar localization studies in Escherichia coli}

Gilles Malherbe',2, David Paul Humphreys' \& Emma Davét,1

\section{ABSTRACT}

Fractionation in Gram-negative bacteria is used to identify the subcellular localization of proteins, in particular the localization of exported recombinant proteins. The process of cell fractionation can be fraught with cross-contamination issues and often lacks supporting data for fraction purity. Here, we compare three periplasm extraction and two cell disruption techniques in different combinations to investigate which process gives uncontaminated compartments from Escherichia coli. From these data, a robust method named PureFrac was compiled that gives pure periplasmic fractions and a superior recovery of soluble cytoplasmic proteins. The process extracts periplasm using cold osmotic shock with magnesium, prior to sonication and ultracentrifugation to separate the cytoplasm from insoluble material. This method handles cells cultivated in various conditions and allows preparation of active proteins in their respective compartments.

\section{METHOD SUMMARY}

This fractionation protocol is a robust method to isolate proteins from subcellular locations from Escherichia coli. The periplasmic, cytoplasmic and membrane fractions are separated without cross-contamination.

\section{KEYWORDS:}

alkaline phosphatase $\cdot$ cold-osmotic shock - export - fractionation • periplasm

${ }^{1} U C B$ Celltech, Slough, UK; ${ }^{2}$ School of Biosciences, University of Kent, Canterbury, UK; *Author for correspondence: emma.dave@ucb.com

BioTechniques 66: 171-178 (April 2019) 10.2144/btn-2018-0135
In bacteria, proteins localize at specific sites to form an elaborate subcellular architecture [1]. Characterizing their locations further develops the understanding of their function, which can be used in various fields including medical research [2-8]. Moreover, using Escherichia coli as a host, recombinant proteins for both academic research and industrial applications can be directed to the periplasm for disulfide bond formation [9], ease of downstream processing [10] or toxic protein expression [11]. The subcellular location can be predicted using bioinformatic tools developed over the past decades such as SignalP [12], PSORTb [13] and SecretomeP [14], but these predictions need to be validated experimentally. To do so, the cells can be fractionated to isolate the proteins in their respective subcellular compartments. The present study focuses on E. coli, a Gramnegative bacterium that has a different cell wall organization compared with Grampositive bacteria $[15,16]$, where proteins can be localized in four different compartments: outer membrane (OM), periplasm, inner membrane (IM) or cytoplasm [16].

Although published fractionation protocols are not wholly different from each other, there appears to be no standardized method to extract all compartments with associated due-diligence against crosscontamination and inconsistency [10]. Subcellular fractionation begins with extracting the periplasm, then the cytoplasm and finally the insoluble fraction that includes membranes and aggregated proteins. Further preparation to isolate the $\mathrm{IM}$ from the OM can also be performed but is out of the scope of this work. The periplasmic extraction is the most critical step of the process since disruption of the IM results in contamination from cytoplasmic proteins. Common methods use either an EDTA-lysozyme strategy $[17,18]$ or cold osmotic shock $[19,20]$, or a combination of both [21]. In the former method, EDTA is used to destabilize the OM [22], allowing the lysozyme to enter the periplasm and hydrolyze the peptidoglycan cell wall. This process subsequently releases the periplasm and leaves the cells as spheroplasts [18]. The second method generates an osmotic shock induced by successively adding a hypertonic solution to weaken the $\mathrm{OM}$, followed by a hypotonic solution to partially disrupt the OM without compromising the integrity of the IM [19].

The second and third steps in the fractionation process result in the recovery of the cytoplasmic and insoluble fraction simultaneously by cell lysis and centrifugation. The risks are poor soluble protein recovery due to incomplete lysis or the use of harsh conditions resulting in loss of soluble protein through aggregation that in turn contaminates the insoluble fraction. The most common cell-lysis techniques used are freeze-thaw cycling and sonication $[10,17]$. The former offers the advantage of treating several samples simultaneously whereas sonication can treat only one sample at a time. Following cell lysis the samples are centrifuged to isolate the insoluble debris such as the membrane fragments and, when present in the cell, protein inclusion bodies.

Obtaining pure fractions is especially important when studying the biology of secretion systems such as the general secretory (Sec) or the twin-arginine translocation (Tat) pathways [23]. To the best of our knowledge, no single study clearly describes, in detail, a robust method to obtain uncontaminated soluble bacterial fractions. For instance, Thein et al. and Tao et al. compared periplasmic fractions obtained by EDTA/lysozyme and cold osmotic shock and demonstrated crosscontamination in each case $[17,24]$. Many publications show no due-diligence to fraction purity $[18,19,21,25,26]$. Some do utilize controls in the form of subcompartment-specific host proteins as purity markers but are incomplete $[27,28]$.

In the present study, different subcellular fractionation processes were evaluated in relation to cross-contam- 
Table 1. List of Escherichia coli K12 strains used in this study.

\begin{tabular}{|c|c|c|c|}
\hline Strain & Phenotype & Genotype & Origin \\
\hline W3110 & Wildtype & F-, lambda-, IN(rrnD-rrnE)1, rph-1 & ATCC 27325 \\
\hline MC4100 & Wildtype & $\begin{array}{l}\text { F-, [araD139]B/r, Del(argF-lac)169, lambda-, e14-, flhD5301, } \Delta \text { (fruK-yeiR)725(fruA25), } \\
\text { relA1, rpsL150(strR), rbsR22, Del(fimB-fimE)632(:IS1), deoC1 }\end{array}$ & CGSC 6152 \\
\hline MC4100 & Tat-null & $\begin{array}{l}\text { F-, [araD139]B/r, Del(argF-lac)169, lambda-, e14-, flhD5301, } \Delta(\text { fruK-yeiR)725(fruA25), } \\
\text { relA1, rpsL150(strR), rbsR22, Del(fimB-fimE)632(::IS1), deoC1, } \Delta \text { tatABCDE }\end{array}$ & Ref [34] \\
\hline
\end{tabular}

Table 2. Expression conditions.

\begin{tabular}{|c|c|c|c|c|c|c|c|}
\hline Condition & $\begin{array}{l}\text { Preculture } \\
\text { medium }\end{array}$ & $\begin{array}{l}\text { Culture } \\
\text { medium }\end{array}$ & $\begin{array}{l}\text { Growth } \\
\text { temperature }\left({ }^{\circ} \mathbf{C}\right)\end{array}$ & $\mathrm{OD}_{600}$ & Feed & $\begin{array}{l}\text { Temperature } \\
\mathrm{PI}\left({ }^{\circ} \mathrm{C}\right)\end{array}$ & Harvest PI (h) \\
\hline 1 & LB & LB & 30 & 0.5 & - & 30 & 2 \\
\hline 2 & LB & LB & 30 & 0.5 & - & 30 & 4 \\
\hline 3 & LB & LB & 37 & 0.5 & - & 37 & 2 \\
\hline 4 & LB & LB & 30 & 0.5 & - & 18 & 16 \\
\hline 5 & $2 x \mathrm{TY}$ & $2 x \mathrm{TY}$ & 30 & 0.5 & - & 30 & 2 \\
\hline 6 & $2 \times \mathrm{TY}$ & $2 \times \mathrm{TY}$ & 37 & 3.5 & Yes & 18 & 16 \\
\hline \multicolumn{8}{|c|}{$\begin{array}{l}\text { The details of the six conditions used in this study are listed by preculture and culture media, growth temperature after inoculation, } \mathrm{OD}_{600} \\
\text { at inoculation as well as growth temperature } \mathrm{PI} \text {, addition of feed at induction and harvest time PI. The feed was diluted } 25 \text { times into the } \\
\text { culture from a stock solution of } 1 \mathrm{M} \text { MOPS pH 7.2, } 40 \% \text { glycerol, } 20 \mathrm{mM} \mathrm{MgSO}_{4}, 20 \mathrm{mM} \mathrm{MgSO}_{4} \text {. } \\
\mathrm{PI} \text { : Post-induction. }\end{array}$} \\
\hline
\end{tabular}

Table 3. List of antibodies used in this study.

\begin{tabular}{|c|c|c|c|c|c|c|c|}
\hline Antibody & Target & Clonality & Species & Conjugation & Dilution & Supplier & Catalog number \\
\hline \multirow[t]{6}{*}{ Primary } & His tag & Polyclonal & Rabbit & HRP & $1 / 2000$ & Universal biologicals & A190-114P \\
\hline & cMyc tag & Monoclonal & Mouse & - & $1 / 2000$ & Abcam & Ab32 \\
\hline & Lacl & Monoclonal & Mouse & - & $1 / 2000$ & Abcam & AB33832 \\
\hline & G6PD & Polyclonal & Rabbit & - & $1 / 2000$ & Assaypro & $33115-05111$ \\
\hline & MBP & Polyclonal & Rabbit & - & $1 / 5000$ & Abcam & AB21144 \\
\hline & DsbA & Monoclonal & Mouse & - & $1 / 1000$ & Abcam & AB106061 \\
\hline \multirow[t]{2}{*}{ Secondary } & Mouse IgG, Fc $\gamma$ & Polyclonal & Goat & HRP & $1 / 2500$ & Jacksonimmuno & 115-036-071 \\
\hline & Rabbit IgG, HC+LC & Polyclonal & Goat & HRP & $1 / 2000$ & Universal biologicals & A120-101P \\
\hline
\end{tabular}

Table 4. Fractionation methods used in this paper.

\begin{tabular}{|l|l|l|}
\hline Method & Periplasmic extraction & Cell disruption \\
\hline Method 1 & Cold osmotic shock & Freeze-thaw cycling \\
\hline Method 2 & Cold osmotic shock with $\mathrm{MgCl}_{2}$ & Freeze-thaw cycling \\
\hline Method 3 & EDTA/lysozyme/cold osmotic shock & Sonication \\
\hline Method 4 & EDTA/lysozyme/cold osmotic shock & Freeze-thaw cycling \\
\hline PureFrac & Cold osmotic shock with $\mathrm{MgCl}_{2}$ & Sonication \\
\hline
\end{tabular}

> ination in order to devise an optimal complete method. Alkaline phosphatase (PhoA) variants were used as reporter proteins to demonstrate either cytoplasmic or periplasmic cellular localization. The former lacks a signal peptide whereas in the latter, PhoA was fused to either a Sec-specific $[28,29]$ or Tat-specific signal peptide $[19,21,26,28,30]$ for export. PhoA is naturally exported by the Sec pathway [28], but has also been shown to export into the periplasm as a fully folded protein via the 
Tat pathway when fused to a TorA signal peptide $[26,28]$. As PhoA contains two disulfide bonds required for activity, for cytoplasmic expression and Tat export where correct folding is a requisite $[26,28]$, the CyDisCo technology (human protein disulfide isomerase PDI and sulfhydryl oxidase from Saccharomyces cerevisiae Erv1p) was utilized [26,29,31-33].

As a negative control that is defective in periplasmic export via Tat, a MC4100 Tat-null mutant [34] was used to test the robustness of the technique. This mutant is further characterized with a phenotype distinct from wildtype (WT), as being prone to lysis, bearing a filamentous morphology and leaky periplasm and thereby a compromised IM $[6,35,36]$.

\section{MATERIALS \& METHODS}

All chemicals, enzymes and protein reagents were supplied by Sigma-Aldrich unless otherwise stated, and all de novo gene synthesis was performed by ATUM Inc.

\section{Strain \& plasmid construction}

The strains E. coli K12 W3110 WT, MC4100 WT and MC4100 Tat-null were used for gene expression studies (Table 1). All cloning and plasmid amplification was performed using TOP10 chemically competent cells (ThermoScientific) according to the manufacturer's recommendations. Gene expression plasmids were constructed using the Golden Gate technology [37]. Initially, the vector pDPH340 [38] was modified by PCR mutagenesis to remove the TypellS restriction site, Bsal in the vector backbone; subsequently Bsal sites were strategically inserted at specific points downstream from the IPTG-inducible tac promoter, to accept either one or two compatible-gene cassettes for in-frame single or polycistronic gene expression.

\section{Protein expression}

Chemically competent cells [39] were transformed with the appropriate plasmid, as outlined in Sambrook and Russel [40], plated onto Lennox agar [40] supplemented with tetracycline $(10 \mu \mathrm{g} / \mathrm{ml})$ and incubated for $16 \mathrm{~h}$ at $37^{\circ} \mathrm{C}$. A preculture was prepared by inoculating $10 \mathrm{ml}$ of selective Lennox medium (LB) [40] or 2xTY [40] with a single colony from a fresh plate, and incubating for $16 \mathrm{~h}$ at $37^{\circ} \mathrm{C}$ with shaking at $220 \mathrm{rpm}$. Subsequently, shake flasks containing $25 \mathrm{ml}$ of selective media and supplemented with cofactors, $\mathrm{MgSO}_{4}$ and $\mathrm{ZnSO}_{4}$ at a final concentration of $0.5 \mathrm{mM}$, were inoculated with the preculture at a starting $\mathrm{OD}_{600}$ of $\sim 0.05$. Flasks were incubated at 30 or $37^{\circ} \mathrm{C}$ with shaking at $220 \mathrm{rpm}$ and the $\mathrm{OD}_{600}$ followed with time. When the $\mathrm{OD}_{600}$ reached 0.5 , gene expression was induced with a final concentration of $100 \mu \mathrm{M}$ IPTG and cultures were incubated at the specific conditions shown in Table 2.

\section{Fractionation methods}

Following protein expression, a volume of culture equivalent to an $\mathrm{OD}_{600}$ of 8 was transferred to a $50-\mathrm{ml}$ tube and centrifuged for $15 \mathrm{~min}$ at $4816 \mathrm{xg}$ at $4^{\circ} \mathrm{C}$. The supernatant was carefully discarded with a pipette and the resulting cell pellet was incubated on ice.

Throughout the process, samples and solutions were incubated on ice and all centrifugations were performed for $3 \mathrm{~min}$ at $20,817 \mathrm{~g}$ at $4^{\circ} \mathrm{C}$ unless otherwise stated. PBS, water and buffers were freshly supplemented with $100 \mathrm{mM}$ of N-Ethylmaleimide (NEM) to trap the thiol-disulfide status during sample processing and with the cOmplete ${ }^{\mathrm{w}}$ Protease Inhibitor Cocktail (Roche) at the recommended dose. To minimize cross-contamination of fractions, all steps requiring the handling, transfer or removal of small volumes of liquid were undertaken using single channel pipettes without disturbing the pellet. Prepared fractions were stored at $-20^{\circ} \mathrm{C}$ until required. The methods are summarized in the Table 4.

\section{Method 1}

The periplasm was extracted by cold osmotic shock and the cells were lysed by freezethaw cycling as described previously [20].

Periplasmic extraction. The cell pellet was washed with $850 \mu \mathrm{l}$ PBS at $\mathrm{pH} 7.4$ ( $\mathrm{NaCl} 137 \mathrm{mM}, \mathrm{KCl} 2.7 \mathrm{mM}, \mathrm{Na}_{2} \mathrm{HPO}_{4}$ $24.2 \mathrm{mM}, \mathrm{KH}_{2} \mathrm{PO}_{4} 5.2 \mathrm{mM}$ ), centrifuged and the supernatant was carefully discarded. The cell pellet was then resuspended in $900 \mu$ l of spheroplast buffer (0.1 M Tris $\mathrm{pH}$ 8.0, $500 \mathrm{mM}$ sucrose, $0.5 \mathrm{mM}$ EDTA pH 8.0), incubated for $5 \mathrm{~min}$, centrifuged and the supernatant carefully discarded. The pellet was then resuspended in $400 \mu \mathrm{l}$ of hypotonic solution (distilled water) and the sample was incubated for $15 \mathrm{~s}$ on ice before

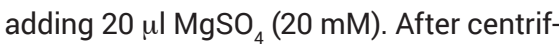
ugation, the resulting periplasmic fraction was carefully transferred to a new tube and the subsequent pellet incubated on ice or stored at $-20^{\circ} \mathrm{C}$.

Cell disruption. The resulting pellet was gently resuspended in $900 \mu$ l of spheroplast buffer before adding lysozyme $(235 \mu \mathrm{g} / \mathrm{ml}$ working concentration) and gently mixed. The suspension was diluted with $900 \mu \mathrm{l}$ distilled water and incubated for $5 \mathrm{~min}$. After centrifugation, the supernatant was carefully discarded and the pellet was resuspended in $1.2 \mathrm{ml}$ Tris pH $8.0(10 \mathrm{mM})$. For cell lysis, the suspension was rapidly freeze-thaw cycled four times in liquid nitrogen for $2 \mathrm{~min}$ and in a $37^{\circ} \mathrm{C}$ water bath for $3 \mathrm{~min}$. After addition of $10 \mathrm{U}$ of benzonase to degrade DNA and $20 \mu \mathrm{l} 1 \mathrm{M} \mathrm{MgSO}_{4}$, the sample was incubated for $10 \mathrm{~min}$, prior to centrifugation for $25 \mathrm{~min}$ at $20,817 \times \mathrm{g}$. The resulting supernatant was carefully transferred to a fresh tube as the cytoplasmic fraction and stored at $-20^{\circ} \mathrm{C}$. The pellet was resuspended in $1 \mathrm{ml}$ Tris $\mathrm{pH}$ $8.0(10 \mathrm{mM})$ and stored as the insoluble fraction at $-20^{\circ} \mathrm{C}$.

\section{Method 2}

Periplasmic extraction. By cold osmotic shock as described in method 1 except $1 \mathrm{mM} \mathrm{MgCl}$ was used instead of water as the hypotonic solution.

Cell disruption. By freeze-thaw cycling as described in method 1.

\section{Method 3}

The periplasm was extracted by EDTA/ lysozyme/cold osmotic shock and the cells were lysed by sonication as described previously [30]

Periplasmic extraction. The cell pellet was washed in $850 \mu$ l PBS, resuspended in $500 \mu \mathrm{l}$ Buffer 1 (100 mM Tris-acetate, $500 \mathrm{mM}$ sucrose, $5 \mathrm{mM}$ EDTA pH 8.0) and diluted with $500 \mu \mathrm{l}$ distilled water before adding $40 \mu$ l lysozyme $(2 \mathrm{mg} / \mathrm{ml})$. After a 5 -min incubation followed by the addition of $20 \mu \mathrm{MgSO}_{4}(1 \mathrm{M})$, the cells were centrifuged and the supernatant was transferred into a fresh tube as the periplasmic fraction.

Cell disruption. The resulting pellet was resuspended in $1 \mathrm{ml}$ Buffer 2 (50 mM Trisacetate $\mathrm{pH}$ 8.2, $250 \mathrm{mM}$ sucrose, $10 \mathrm{mM}$ $\mathrm{MgSO}_{4}, 1 \mathrm{U} / \mathrm{ml}$ benzonase), centri- 


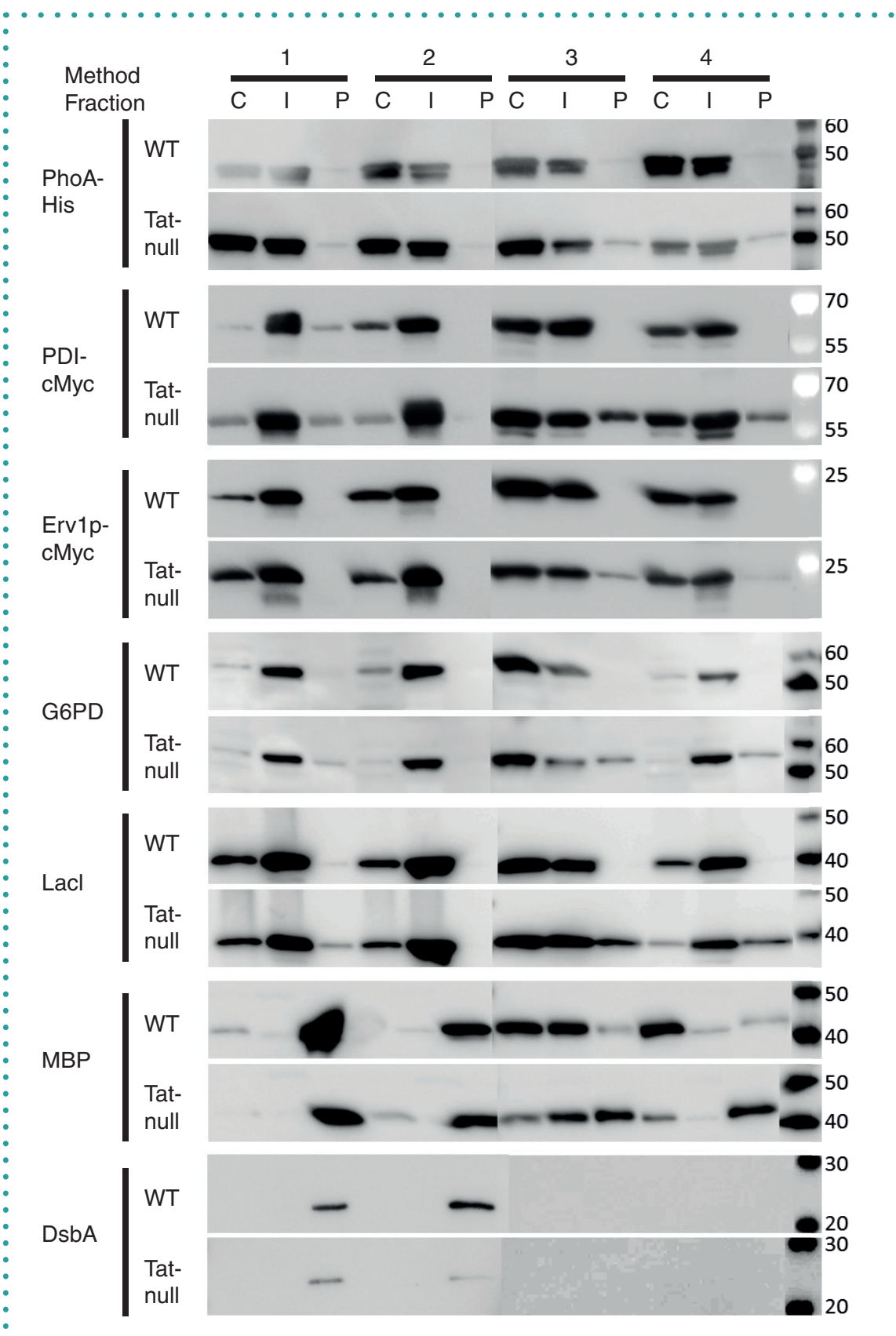

Figure 1. Evaluation of periplasmic and cytoplasmic extraction methods. W3110 WT and MC4100 Tat-null strains co-expressed cytoplasmic His-tagged PhoA and C-terminally cMyc-tagged Erv1p and PDI proteins. The cells were fractionated according to methods 1 (cold osmotic shock and freezethaw cycling), 2 (cold osmotic shock with magnesium and freeze-thaw cycling), 3 (EDTA/lysozyme/ cold osmotic shock and sonication) and 4 (EDTA/lysozyme/cold osmotic shock and freeze-thaw cycling). The fractions are represented as cytoplasmic (C), insoluble (I) and periplasmic (P). Western blots show from top to bottom, the detection of PhoA, PDI, Erv1p, G6PD, Lacl, MBP and DsbA proteins as detected by anti-His, anti-cMyc, anti-cMyc, anti-G6PD, anti-Lacl, anti-MBP and anti-DsbA antibodies, respectively. Molecular weight markers are indicated on the right in $\mathrm{kDa}$. WT: Wildtype.

fuged for $5 \mathrm{~min}$, and the supernatant was carefully discarded. The pellet was resuspended in $750 \mathrm{ml}$ Buffer 3 (Trisacetate pH 8.2, $2.5 \mathrm{mM}$ EDTA pH 8.0) and the suspension was sonicated ( 5 cycles once resuspended in $1 \mathrm{ml}$ Buffer 3, was reserved as the insoluble fraction.

\section{Method 4}

Periplasmic extraction. By EDTA/lysozyme/ cold osmotic shock as described in method 3.

Cell disruption. By freeze-thaw cycling as described in method 1.

\section{Western blotting}

Samples were loaded onto 4-20\% Novex Tris-glycine gels (ThermoScientific) according to the manufacturer's instructions with the molecular weight markers MagicMark XP (ThermoScientific) and PageRuler Plus Prestained Protein Ladder (ThermoScientific) before separation by electrophoresis at $100 \mathrm{~V}$ for $100 \mathrm{~min}$ in Novex (1X) Tris-glycine buffer (ThermoScientific). The proteins were dry transferred onto a PVDF membrane using the iBlot system (ThermoScientific) according to the manufacturer's recommendations. Immunostaining was carried out according to Sambrook and Russel [40] using antibodies as listed in the Table 3. Detection was performed using Pierce"' ECL Plus Western Blotting Substrate (Life Technologies) and imaged by the ImageQuant LAS 4000 device (GE Healthcare).

\section{RESULTS \& DISCUSSION}

\section{Identification of a robust}

\section{fractionation method}

For cytoplasmic expression, the leaderless PhoA (48.3 kDa), Ervlp (22.9 kDa) and PDI (56.7 kDa) were co-expressed from an IPTGinducible polycistronic construct controlled by the tac promoter and where Lacl $(38.7 \mathrm{kDa})$ was used as the repressor. PhoA and the CyDisCo components were tagged with C-terminal His and cMyc tags, respectively, to aid identification in Western blots. All four proteins therefore served as cytoplasmic markers. The endogenous proteins, the cytoplasmic glucose-6-phosphate dehydrogenase (G6PD, $55.7 \mathrm{kDa}$ ) and two periplasmic proteins, maltose-binding protein (MBP, $43.4 \mathrm{kDa}$ ) and protein disulfide isomerase DsbA (23.1 kDa) [41-43], were also used as native host markers to validate fraction purity.

Three periplasmic extraction methods, cold-osmotic shock, cold-osmotic shock with $\mathrm{MgCl}_{2}$ and EDTA/lysozyme/coldosmotic [30]; and two cell disruption 
techniques, sonication [30] and freeze-thaw cycles, were compared in combinations to assess fraction purity (Table 4). Protein localization and cross-contamination was monitored by Western blot of overexpressed proteins and selected markers.

Cytoplasmic PhoA, Erv1p and PDI were co-expressed in W3110 WT and MC4100 tat-null strains as outlined in Table 2 (condition 4) and the cells were fractionated. As shown in Figure 1, the periplasmic fraction isolated by cold-osmotic shock (method 1) presented minor bands with PDI and Lacl and, to a lesser extent, PhoA and G6PD in both strains indicating some cross-contamination from the cytoplasm. The markers MBP and DsbA were located in the periplasmic fractions as anticipated, confirming a successful extraction of the periplasm. However, cytoplasmic contamination can be completely avoided by the use of $\mathrm{MgCl}_{2}$ during the cold-osmotic shock (method 2) while the periplasmic markers are still extracted effectively (Figure 1). The addition of $\mathrm{MgCl}_{2}$ to the hypotonic solution has previously been suggested [44] because magnesium plays a major role in maintaining the stability of the OM $[22,45]$. It therefore appears that the osmotic shock step with $\mathrm{Mg}$ used in this study resulted in the disruption of only the OM without affecting the integrity of the IM. However, minor bands of periplasmic MBP were still detected in the cytoplasmic and insoluble fractions (Figure 1), presumably from lysis of a small proportion of intact cells that escaped processing in the periplasmic extraction step.

By contrast, when using the EDTA/ lysozyme/cold-osmotic shock (method 3 and 4), an incomplete periplasmic extraction was detected for both strains. DsbA was not detected and MBP was only partially detected in the periplasmic fraction, both suggestive of ineffective periplasmic extraction. Moreover, with this method, all cytoplasmic markers were detected in the periplasmic fractions of the Tat-null strain, suggesting that this method can be suboptimal for some strains. The cytoplasmic contamination can be explained by a disrupted IM because of the destabilized cell wall; phospholipids permeabilization of the OM due to cation chelation by the EDTA [22] and PG digestion by the lysozyme. Overall, due to cross-contamination, the EDTA/ lysozyme/cold-osmotic shock technique can lead to false-negative and false-positive conclusions and therefore is not fit for this purpose.

For the isolation of cytoplasmic fractions, two methodologies, freeze-thaw cycling and sonication, were compared. Generally, sonication (method 3) appeared to be superior with notably higher recovery of soluble cytoplasmic proteins as indicated by PDI, Erv1p, G6PD and Lacl (Figure 1). The proteins detected in the insoluble fractions most likely came from unlysed cells or prefractionation aggregates. Benzonase was essential to liquify the lysate by DNA degradation with freeze-thaw cycling but was not required for sonication.

In conclusion, cold-osmotic shock with $\mathrm{MgCl}_{2}$ appears to be the superior method for periplasmic extraction while sonication gave the optimal results for cytoplasmic recovery. These two techniques were subsequently tested together in a single new method.

\section{Validation of the composite method}

The optimal method, consisting of coldosmotic shock with $\mathrm{MgCl}_{2}$ and sonication, named PureFrac, is described in Table 4 and Supplementary Materials. To assess the extraction of a recombinant secreted protein from periplasm using PureFrac, the periplasmic PhoA (fused to a TorA-signal peptide) was co-expressed with PDI and Erv1p in WT and Tat-null strains. Such cells were cultivated in varying settings (Table 2 ) that are commonly used to overexpress proteins in the literature $[18,19,25,26,32,33,38]$ to test whether growth conditions affect cross-contamination propensity.

As shown in Figure 2A, PhoA was only observed in the periplasmic fractions of WT cells indicating exported protein but to varying degrees, this being dependent on the growth parameters used. Culture condition 2 gave the optimal level of exported PhoA. As expected, PhoA was not observed in the periplasm of the Tat-null strain confirming Tat specific export [26] and demonstrating fraction purity. Discounting proteins present in the insoluble fraction, the cytoplasmic markers PDI, Erv1p, Lacl, and the periplasmic marker MBP were all observed in their predicted fractions for both strains (Figure 2B).

To further validate the utility of PureFrac, PhoA was expressed in the cytoplasm (no signal peptide) and periplasm via both Sec and Tat export pathways (OmpA and TorA signal peptides, respectively). The cytoplasmic and Tat-exported PhoA were co-expressed with PDI and Erv1p. The MC4100 WT and Tat-null strains were cultivated according to condition 2 (Table 2),

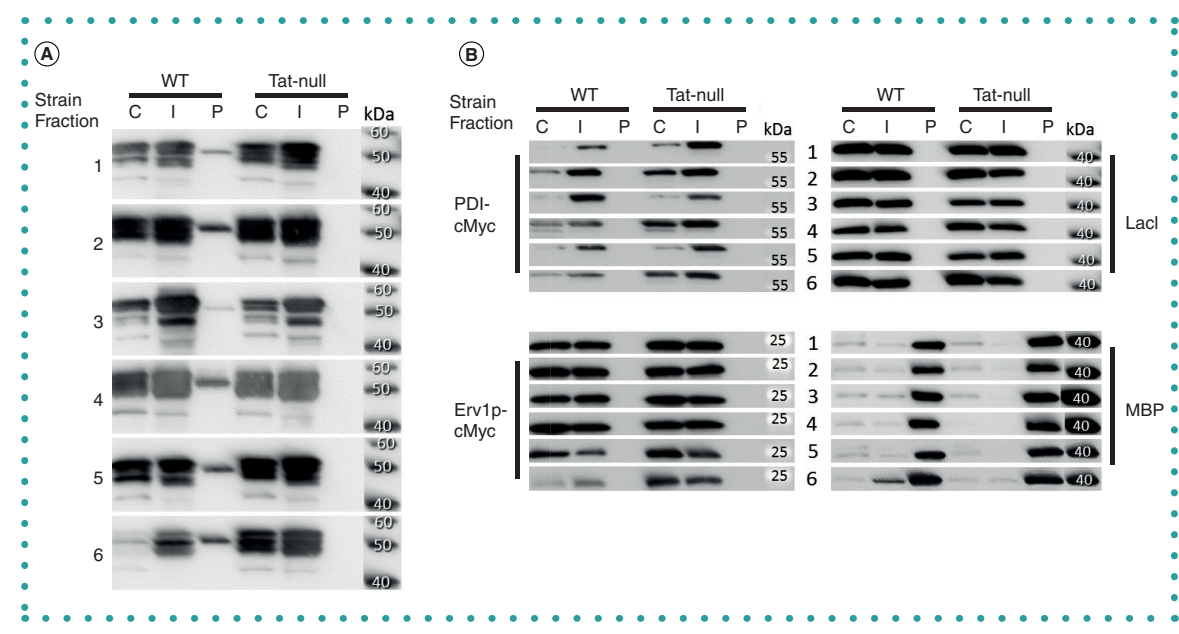

Figure 2. Evaluation of optimized subcellular fractionation method. W3110 WT and MC4100 Tat-null strains co-expressing periplasmic (Tat pathway specific) His-tagged Tor $\mathrm{A}_{\mathrm{SP}}-\mathrm{PhoA}$ and C-terminally cMyc-tagged Erv1p and PDI were grown in different conditions: induced in LB (1) for $2 \mathrm{~h}$ at $30^{\circ} \mathrm{C}$ or (2) for $4 \mathrm{~h}$ at $30^{\circ} \mathrm{C}$, (3) for $2 \mathrm{~h}$ at $37^{\circ} \mathrm{C}$, (4) for $16 \mathrm{~h}$ at $18^{\circ} \mathrm{C}$ or (5) induced in $2 \mathrm{x} \mathrm{TY}$ for $2 \mathrm{~h}$ at $30^{\circ} \mathrm{C}$ or (6) induced in fed-batch culture for $16 \mathrm{~h}$ at $18^{\circ} \mathrm{C}$. The cells were then fractionated using PureFrac method into the cytoplasmic (C), insoluble ( $I$ ) and periplasmic $(P)$ fractions. (A) Western blots of PhoA-His detected by anti-His antibodies. (B) Western blot showing Erv1p, PDI, Lacl and MBP proteins detected by anti-cMyc, anti-cMyc, anti-Lacl and anti-MBP antibodies respectively. Molecular weight markers are indicated in $\mathrm{KDa}$ on the right of each blot. WT: Wildtype. 


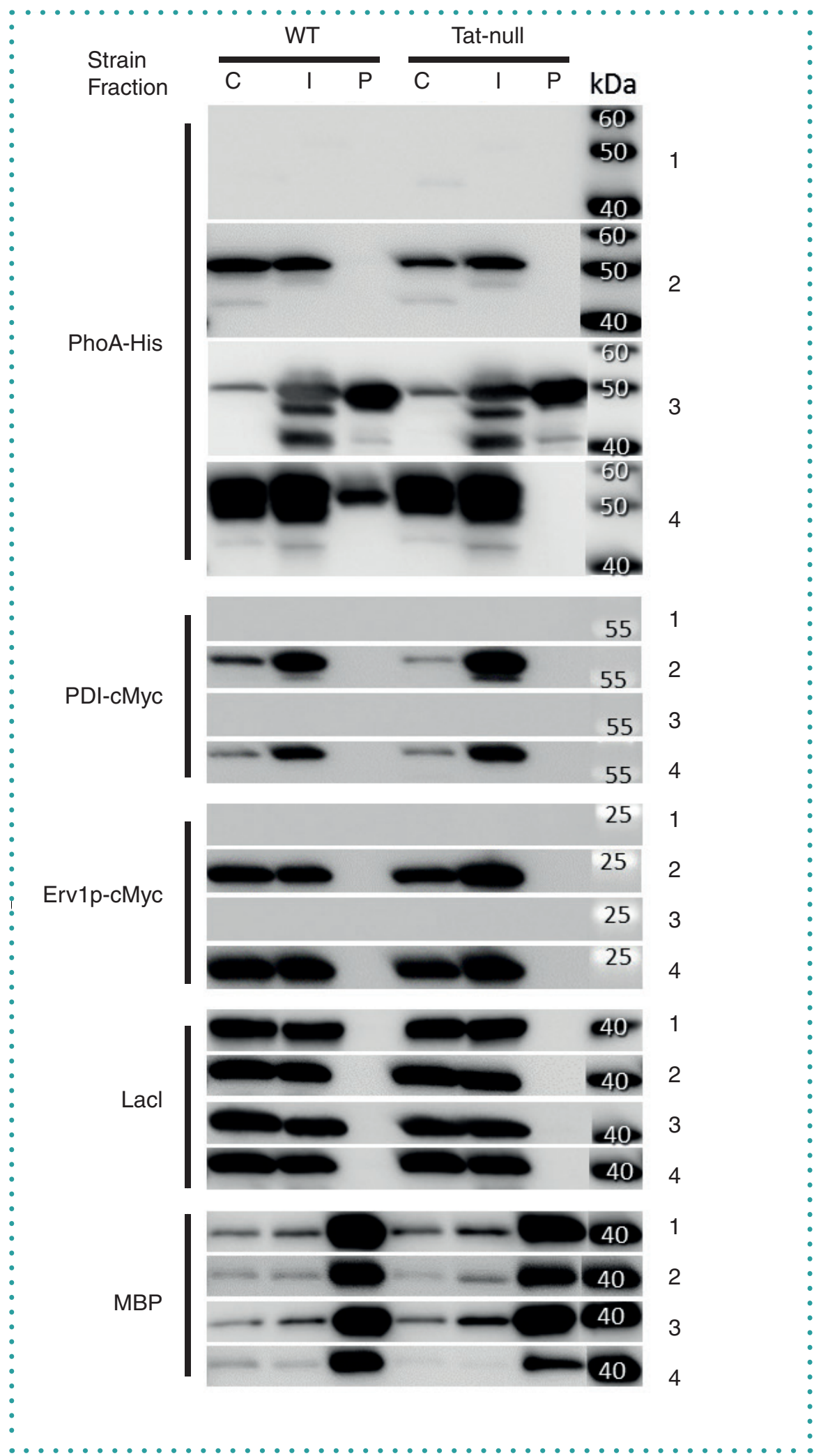

Figure 3. Validation of PureFrac. An empty vector (1), cytoplasmic His-tagged PhoA (2), periplasmic (Sec pathway) $\mathrm{OmpA}_{\mathrm{SP}}-\mathrm{PhoA}(3)$ and periplasmic (Tat pathway) $\operatorname{TorA}_{\mathrm{SP}}-\mathrm{PhoA}$ co-expressed with cMyc-tagged PDI and Erv1p (4) were expressed in MC4100 WT and Tat-null strains. The cells were then fractionated using PureFrac method into the cytoplasmic $(C)$, insoluble $(I)$ and periplasmic $(P)$ fractions. Western blots show PhoA-His, Erv1p, PDI, Lacl and MBP proteins detected by anti-His, anti-cMyc, anti-cMyc, anti-Lacl and anti-MBP antibodies, respectively. Molecular weight markers are indicated on the right in $\mathrm{kDa}$. WT: Wild type.
- which gave optimal Tat export (Figure 2), and subsequently fractionated according to the PureFrac protocol. In Figure 3, cytoplasmic PhoA was not detected in the periplasm as anticipated, consistent with previous observations (Figure 1). As predicted, PhoA corresponding to Sec-specific export (OmpA $\left.\mathrm{SP}_{\mathrm{SP}}-\mathrm{PhoA}\right)$ was secreted into the periplasm in both strains whereas Tat-specific export of PhoA (TorA $\mathrm{SP}_{\mathrm{SP}}-\mathrm{PhoA}$ ) was only observed in the WT strain. All cytoplasmic (PDI, Erv1p, Lacl) and periplasmic (MBP) markers were observed in their expected subcellular fractions, further supporting the robustness of the fractionation method. Furthermore, this protocol is not so aggressive as to denature proteins, as demonstrated by active PhoA in periplasmic extracts of $\mathrm{Sec}$ and Tat (data not shown).

We have demonstrated the robustness of the PureFrac method to isolate pure fractions and we show that markers must always be utilized as controls to highlight any cross-contamination artefacts. However, some steps may be further optimized, for example solving the issue of unlysed cells or prefractionation aggregates. Also, the insoluble preparation step calls for a 186,000 g ultracentrifugation step, which could be mitigated to a lower speed of $30,000 \mathrm{~g}$ with a wash step to remove all potential cytoplasmic contaminating material $[46,47]$. In our hands, comparable fraction purity was obtained in export localization studies with human growth hormone, superfolder GFP, $\beta$-galactosidase, antibody fragments and PaoA (data not shown). We believe that reliable conclusions can be drawn from observations made using this PureFrac technique and specific controls.

\section{FUTURE PERSPECTIVE}

The present study highlights the strengths and weaknesses of the main subcellular fractionation steps from current published protocols. To the best of our knowledge, a comparison of this scale has never been published that identifies the steps that are fraught with cross-contamination and inevitably lead to false data and lack of reproducibility. With this in mind, we have identified processing steps that can generate accurate data and in turn, compiled an effective fractionation protocol 
which we hope researchers would recognize for its superior properties and increasingly implement as their 'go to' method. Irrespective of which protocol a researcher uses, we have emphasized the importance of using specific markers as controls, to help identify potential risks at each step.

As PureFrac was developed with a Gramnegative bacterium, we have demonstrated the versatility of this method by application to a strain with a compromised envelope. It is therefore conceivable that this protocol could be applied to other E. coli mutants or other Gram-negative bacterial species, thus expanding its value.

\section{AUTHOR CONTRIBUTIONS}

GM conceived, designed, performed all the experiments and wrote the paper. The study was supervised by DPH and ED who provided guidance and advice by assisting experiment design, data interpretation, manuscript evaluation and edition.

\section{ACKNOWLEDGMENTS}

The authors would like to thank Colin Robinson for kindly sharing the MC4100 Tat-null strain and members of his team for sharing of periplasmic expression methods.

\section{FINANCIAL \& COMPETING INTERESTS DISCLOSURE}

The research leading to these results has received funding from the People Programme (Marie Skłodowska-Curie Actions) of the European Union's Horizon 2020 Programme under REA grant agreement no. 642836. This material reflects only the authors' views and the Union is not liable for any use that may be made of the information contained therein. DPH holds UCB shares. The authors have no other relevant affiliations or financial involvement with any organization or entity with a financial interest in or financial conflict with the subject matter or materials discussed in the manuscript apart from those disclosed.

No writing assistance was utilized in the production of this manuscript.

\section{SUPPLEMENTARY DATA}

To view the supplementary data that accompany this paper please visit the journal website at: www.future-science. com/doi/suppl/10.2144/btn-2018-0135

\section{OPEN ACCESS}

This work is licensed under the AttributionNonCommercial-NoDerivatives 4.0 Unported License. To view a copy of this license, visit http://creativecommons.org/licenses/ by-nc-nd/4.0/

\section{REFERENCES}

1. Rudner DZ, Losick R. Protein subcellular localization in bacteria. Cold Spring Harb. Perspect. Biol. 2(4), a000307 (2010).

2. Alley MR, Maddock JR, Shapiro L. Polar localization of a bacterial chemoreceptor. Genes \& Develop. 6(5), 825-836 (1992).

3. Tomlinson S, Taylor PW, Morgan BP, Luzio JP. Killing of Gram-negative bacteria by complement. Fractionation of cell membranes after complement $\mathrm{C} 5 \mathrm{~b}-9$ deposition on to the surface of Salmonella minnesota Re595. Biochem. J. 263(2), 505-511 (1989).

4. Santini CL, Ize B, Chanal A, Müller M, Giordano G, Wu LF. A novel sec-independent periplasmic protein translocation pathway in Escherichia coli. EMBO J. 17(1), 101-112 (1998).

5. Chaput $\mathrm{C}$, Ecobichon $\mathrm{C}$, Cayet $\mathrm{N}$ et al. Role of AmiA in the morphological transition of Helicobacter pylori and in immune escape. PLoS Pathog. 2(9), e97 (2006).

6. Bernhardt TG, De Boer PaJ. The Escherichia coli amidase AmiC is a periplasmic septal ring component exported via the twin-arginine transport pathway. Mol. Microbiol. 48(5), 1171-1182 (2003)

7. Kamitani S, Akiyama Y, Ito K. Identification and characterization of an Escherichia coli gene required for the formation of correctly folded alkaline phosphatase, a periplasmic enzyme. EMBO J. 11(1), 57-62 (1992).

8. Quan S, Koldewey P, Tapley T et al. Genetic selection designed to stabilize proteins uncovers a chaperone called Spy. Nat. Struct. Mol. Biol. 18(3), 262-269 (2011).
9. Collet JF, Bardwell JC. Oxidative protein folding in bacteria. Mol. Microbiol. 44(1), 1-8 (2002).

10. Balasundaram B, Harrison S, Bracewell DG. Advances in product release strategies and impact on bioprocess design. Trends Biotechnol. 27(8), 477-485 (2009).

11. Rosano GL, Ceccarelli EA. Recombinant protein expression in Escherichia coli: advances and challenges. Front. Microbiol. 5, 172 (2014).

12. Nielsen $H$. Predicting secretory proteins with SignalP. In: Protein Function Prediction: Methods and Protocols. Kihara D (Ed.). Springer, NY, USA 59-73 (2017).

13. Yu NY, Wagner JR, Laird MR et al. PSORTb 3.0: improved protein subcellular localization prediction with refined localization subcategories and predictive capabilities for all prokaryotes. Bioinformatics (Oxford, England) 26(13), 1608-1615 (2010).

14. Bendtsen JD, Kiemer L, Fausbøll A, Brunak S. Non-classical protein secretion in bacteria. BMC Microbiol. 5(1), 58 (2005).

15. GD Shockman A, Barren JF. Structure, function, and assembly of cell walls of gram-positive bacteria. Ann. Rev. Microbiol. 37(1), 501-527 (1983).

16. Costerton JW, Ingram JM, Cheng KJ. Structure and function of the cell envelope of Gram-negative bacteria. Bacteriological Rev. 38(1), 87-110 (1974).

17. Thein M, Sauer G, Paramasivam N, Grin I, Linke D. Efficient subfractionation of Gram-negative bacteria for proteomics studies. J. Proteome Res. 9(12), 6135-6147 (2010).

18. Pierce JJ, Turner C, Keshavarz-Moore E, Dunnill P. Factors determining more efficient large-scale release of a periplasmic enzyme from $E$. coli using lysozyme. $J$. Biotechnol. 58(1), 1-11 (1997).

19. Kang DG, Kim CS, Seo JH et al. Coexpression of molecular chaperone enhances activity and export of organophosphorus hydrolase in Escherichia coli. Biotechnol. Prog. 28(4), 925-930 (2012).

20. Manoil C, Beckwith J. A genetic approach to analyzing membrane protein topology. Science ( $N Y, U S A)$ 233(4771), 1403-1408 (1986).

21. Alanen HI, Walker KL, Lourdes Velez Suberbie M et al. Efficient export of human growth hormone, interferon alpha2 $\mathrm{b}$ and antibody fragments to the periplasm by the Escherichia coli Tat pathway in the absence of prior disulfide bond formation. Biochim. Biophys. Acta. 1853(3), 756-763 (2015)

22. Clifton LA, Skoda MW, Le Brun AP et al. Effect of divalent cation removal on the structure of Gram-negative bacterial outer membrane models. Langmuir 31(1), 404-412 (2015).

23. Green ER, Mecsas J. Bacterial secretion systems: an overview. Microbiol. Spectr. 4(1), (2016).

24. Tao K. Subcellular localization and in vivo oxidation-reduction kinetics of thiol peroxidase in Escherichia coli. FEMS Microbiol. Lett. 289(1), 41-45 (2008).

25. Pechsrichuang $P$, Songsiriritthigul $C$, Haltrich D et al. OmpA signal peptide leads to heterogenous secretion of B. subtilis chitosanase enzyme from $E$. coli expression system. Springerplus 5(1), 1200 (2016).

26. Matos CF, Robinson C, Alanen $\mathrm{HI}$ et al. Efficient export of prefolded, disulfide-bonded recombinant proteins to the periplasm by the Tat pathway in Escherichia coli CyDisCo strains. Biotechnol. Prog. 30(2), 281-290 (2014).

27. Zhang Z, Tang R, Zhu D, Wang W, Yi L, Ma L. Non-peptide guided auto-secretion of recombinant proteins by super-folder green fluorescent protein in Escherichia coli. Sci. Rep. 7(1), 6990 (2017)

\section{EXECUTIVE SUMMARY}

- This article describes a robust sub-cellular fractionation method to investigate protein localization in Escherichia coli.

- The method uses cold-osmotic shock with $\mathrm{MgCl}_{2}$ to extract the periplasm and sonication for cell disruption followed by ultracentrifugation to separate the cytoplasm from the membranes and inclusion bodies.

- This method is robust enough to obtain pure cytoplasmic and periplasmic fractions in various expression conditions and a mutant strain with a compromised cell envelope.

- Subcellular protein localization can be achieved using this technique to assess the secretion of endogenous and recombinant proteins.

- Periplasmic fractions extracted by the EDTA/lysozyme/cold-osmotic shock method were contaminated by cytoplasmic proteins and do not contain all periplasmic proteins tested.

- Periplasmic fractions extracted by the cold-osmotic shock method were contaminated by cytoplasmic proteins.

- More soluble cytoplasmic proteins can be recovered using sonication than freezethaw cycles. 
28. Fisher AC, Kim JY, Perez-Rodriguez $\mathrm{R}$ et al. Exploration of twin-arginine translocation for expression and purification of correctly folded proteins in Escherichia coli. Microb. Biotechnol. 1(5), 403-415 (2008).

29. Hatahet F, Nguyen VD, Salo KE, Ruddock LW. Disruption of reducing pathways is not essential for efficient disulfide bond formation in the cytoplasm of $E$. coli. Microb. Cell Fact. 9, 67 (2010).

30. Jones AS, Austerberry JI, Dajani R et al. Proofreading of substrate structure by the twin-arginine translocase is highly dependent on substrate conformational flexibility highly dependent on substrate conformational flexibility
but surprisingly tolerant of surface charge and hydrophobicity changes. Biochim. Biophys. Acta. 1863(12), 3116-3124 (2016).

31. Gaciarz A, Ruddock LW. Complementarity determining regions and frameworks contribute to the disulfide bond independent folding of intrinsically stable ScFv. PLOS One 12(12), e0189964 (2017).

32. Gaciarz A, Khatri NK, Velez-Suberbie ML et al. Efficient soluble expression of disulfide bonded proteins in the cytoplasm of Escherichia coli in fed-batch fermentations on chemically defined minimal media. Microb. Cell Fact. 16(1), 108 (2017).

33. Roth R, Van Zyl P, Tsekoa T et al Co-expression of sulphydryl oxidase and protein disulphide isomerase in Escherichia coli allows for production of soluble CRM197. cherichia coli allows for production of soluble
J. Appl. Microbiol. 122(5), 1402-1411 (2017).

34. Wexler M, Sargent F, Jack RL et al. TatD is a cytoplasmic protein with DNase activity. No requirement for TatD family proteins in sec-independent protein export. $J$. Biol. Chem. 275(22), 16717-16722 (2000).
35. Ize B, Porcelli I, Lucchini S, Hinton JC, Berks BC, Palmer T. Novel phenotypes of Escherichia coli tat mutants revealed by global gene expression and phenotypic analysis. J. Biol. Chem. 279(46), 47543-47554 (2004).

36. Stanley NR, Findlay K, Berks BC, Palmer T. Escherichia coli strains blocked in Tat-dependent protein export exhibit pleiotropic defects in the cell envelope. J. Bacteriol. 183(1), 139-144 (2001).

37. Engler C, Kandzia R, Marillonnet S. A one pot, one step, precision cloning method with high throughput capability. PLoS One 3(11), e3647 (2008)

38. Ellis $M$, Patel $P$, Edon $M$, Ramage W, Dickinson $R$ Humphreys DP. Development of a high yielding $E$. coli periplasmic expression system for the production of humanized Fab' fragments. Biotechnol. Prog. 33(1), 212-220 (2017)

39. Chung CT, Niemela SL, Miller RH. One-step preparation of competent Escherichia coli: transformation and storage of bacterial cells in the same solution. Proc. Nat Acad. Sci. USA 86, 2172-2175 (1989).

40. Sambrook J, Russel DW. Molecular Cloning: A Laboratory Manual. $2^{\text {nd }}$ Ed., Cold Spring Harbor Laboratory Press, (2001).

41. Dalbey RE, Von Heijne G. In: Protein Targeting, Transport, and Translocation, Elsevier, Academic Press 5-35 (2002).

42. Bassford PJJ. Export of the periplasmic maltose-bind ing protein of Escherichia coli. J. Bionenerg. Biomembr. 22(3), 401-439 (1990).

43. Jonda S, Huber-Wunderlich M, Glockshuber R, Mössner E. Complementation of DsbA deficiency with secreted thioredoxin variants reveals the crucial role of an efficient dithiol oxidant for catalyzed protein folding in the bacterial periplasm. EMBO J. 18(12), 3271-3281 (1999)

44. El Yaagoubi A, Kohiyama M, Richarme G. Localization of DnaK (chaperone 70) from Escherichia coli in an osmotic-shock-sensitive compartment of the cytoplasm. J. Bacteriol. 176(22), 7074-7078 (1994).

45. Neidhardt FC, Curtiss R, Ingraham JL et al. Escherichia coli and Salmonella: Cellular and Molecular Biology. ASM Press, Washington, D.C. 1, (1996)

46. Wolf-Watz H, Normark S, Bloom GD. Rapid method for isolation of large quantities of outer membrane from Escherichia coli and its application to the study of envelope mutants. J. Bacteriol. 115(3), 1191 (1973).

47. Koga $T$, Kawata $T$. Isolation and characterization of the outer membrane from Vibrio parahaemolyticus. J. Gen. Microbiol. 129(10), 3185-3196 (1983). 